\title{
Envisioning Materials Research: Finding a New Visual Voice
}

The interdisciplinary nature of materials research requires that scientists communicate to colleagues who come from various fields of expertise. A major form of communication is through images. Following is an array of materials images that pay particular attention to how scientific information is presented along with the excitement it engenders. Lighting, props (e.g., to show scale), and sample preparation are utilized to show viewers how to look at the image and where to look.

FELICE FRANKEL
Felice Frankel, science photographer, is a research scientist at the Massachusetts Institute of Technology (MIT) and a fellow of the American Association for the Advancement of Science. She is co-author with George M. Whitesides of On the Surface of Things: Images of the Extraordinary in Science (Chronicle Books, San Francisco, 1997). Her photography, taken in collaboration with researchers, has appeared on the covers and pages of numerous publications, including Nature, Science, Scientific American, Discover, and Newsweek. The images reproduced here are from Frankel's book, Envisioning Science: The Design and Craft of the Science Image (MIT Press, Cambridge, MA, 2002), which shows researchers how to communicate the beauty and dynamism of their work in the physical world to their colleagues and the public. She and colleagues are planning the second MIT Image and Meaning Conference in 2005, where researchers of all disciplines will gather with graphic artists to discover new visual expressions of science and technology (Web site: web.mit.edu/i-m).
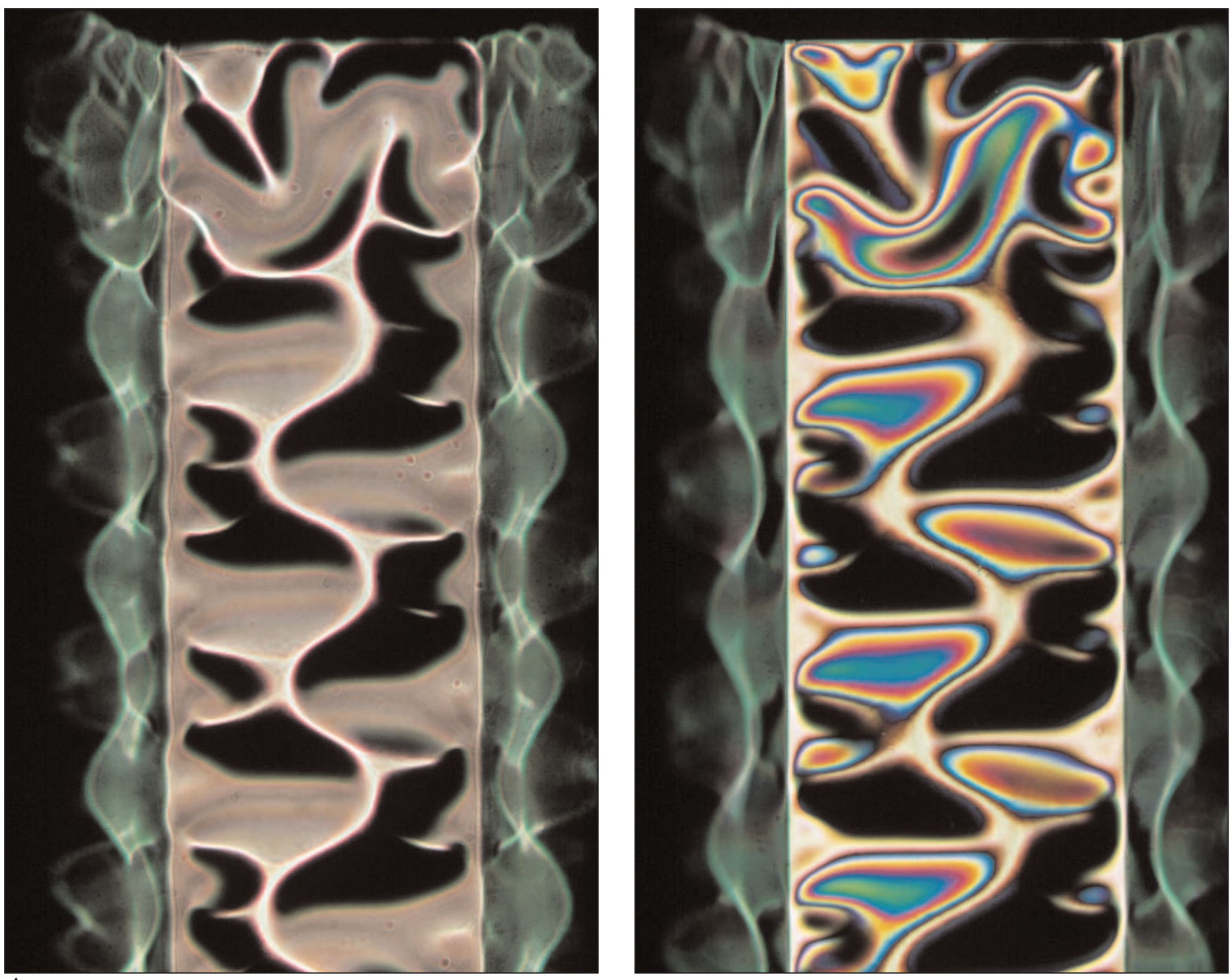

$\Delta$

\section{Microfluidic Device}

Description: Palladium film (0.2 mm thick) deposited on silicon oxide membranes $1 \mathrm{~mm}$ thick and $500 \mathrm{~mm}$ wide. Silicon oxide is under compressive stress, causing the membranes to buckle.

Lighting: Nomarski differential contrast (also called differential interference contrast) is a tool to show form and structure. The photographs show a buckling palladium membrane at different Nomarski settings. In the figure on the right, the colors reveal that the sample is under stress.

Researchers: Klavs Jensen and Aleks Franz, Massachusetts Institute of Technology. 


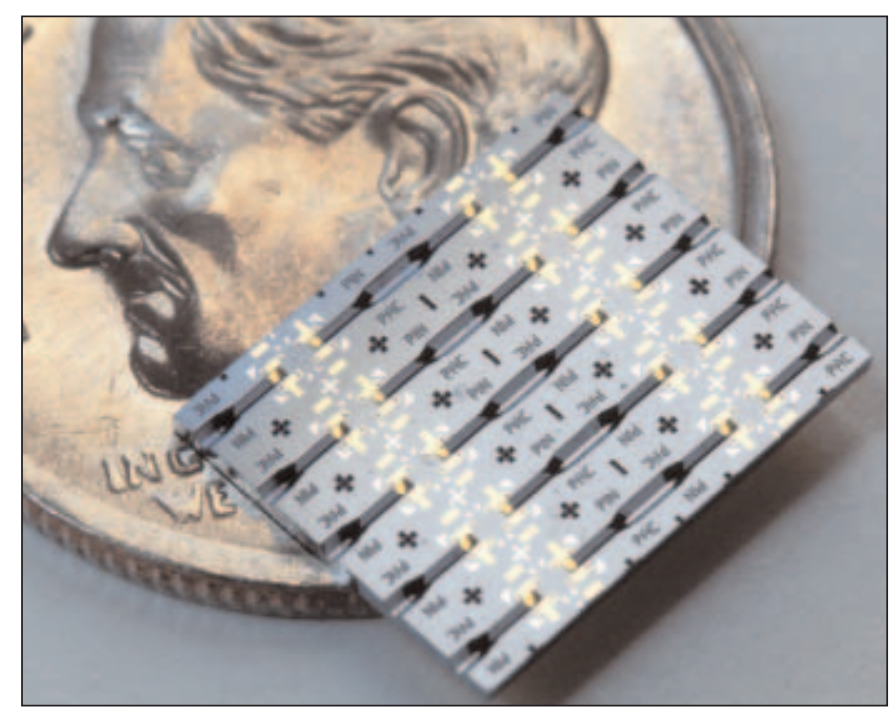

\section{Controlled-Release Microchip >}

Description: Microchips designed for drug delivery.

Sample Preparation: In order to tell a visual story, three elements are combined in the image. Displayed upon a background of a wafer fabricated from a series of small chips are two individual chips and the underside of a second wafer, revealing the holes for drug delivery.

Researchers: Robert Langer, Massachusetts Institute of Technology; from J.T. Santini Jr., A.C. Richards, R. Scheidt, M.J. Cima, and R. Langer, Angew, Chem., Int. Ed. Engl. 39 (2000) p. 2396.

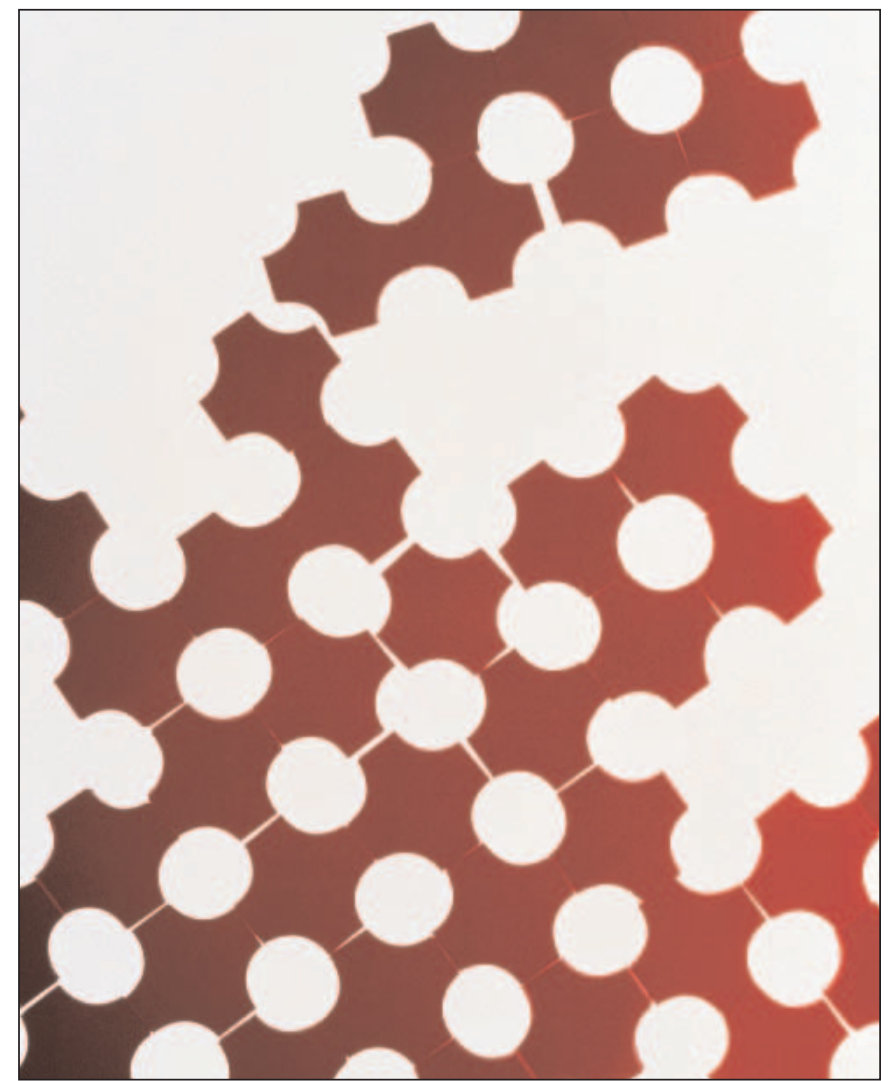

\section{Integrated Optical Components}

Description: Microchip containing 20 optical submounts, fabricated on a silicon wafer. Each submount is used as a platform for PIN photo detectors used in optical communications systems. The large groove is used to align the input fiber to the photodetector so that the gold-coated mirror at the end of the groove can direct light from the fiber to the detector.

Props: To show scale, a coin is typically displayed adjacent to the item of interest. To direct attention to the subject-in this case, the microchipthe sample is placed on top of the dime in an image that displays the full chip with only part of the dime underneath.

Researcher: Alice White, Bell Labs; from A.E. White, Optics and Photonic News 11 (March 2000) p. 26.

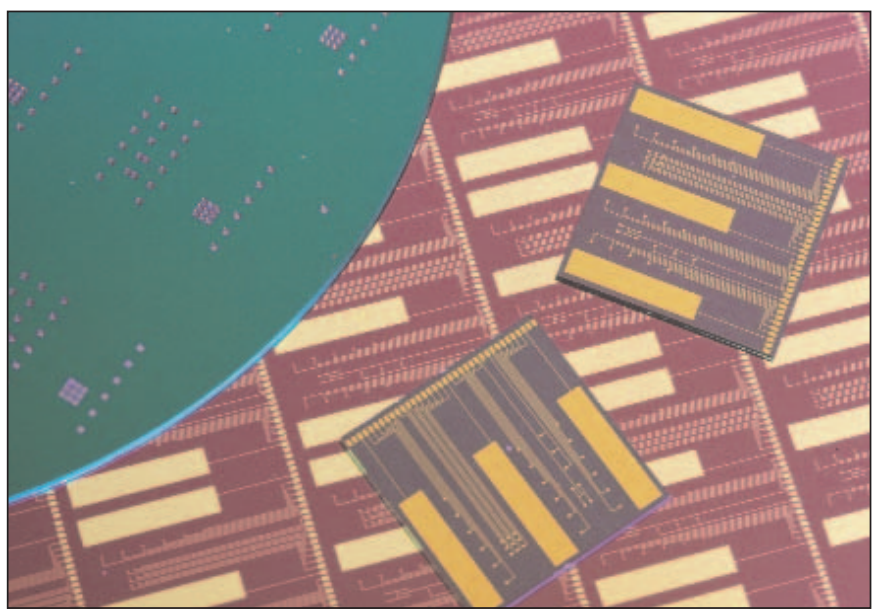

\section{Cross-Shaped Self-Assembled Structure}

Description: Self-assembling, $4 \mathrm{~mm}$ transparent polymer shapes floating at the interface between two liquids.

Lighting: To illuminate transparent materials, a lightbox is placed beneath the object to transmit light through the sample. The border of the container holding the liquid and plastic pieces is cropped out of the photo, drawing attention to the crosslike structures as they come together.

Researchers: George M. Whitesides, Harvard University; from N. Bowden, A. Terfort, and G.M. Whitesides, Science 276 (1997) p. 233.

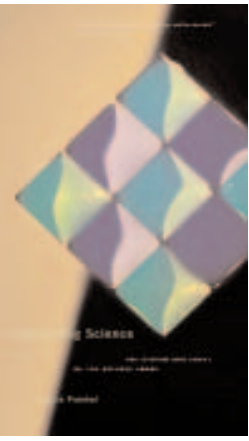

Images reproduced with permission

Envisioning Science: The Design and Craft of the Science Image

Felice Frankel

(MIT Press, Cambridge, MA, 2002) 